\title{
Identification of a missense mutation in the bovine $A B C G 2$ gene with a major effect on the QTL on chromosome 6 affecting milk yield and composition in Holstein cattle
}

\author{
Miri Cohen-Zinder, ${ }^{1,4}$ Eyal Seroussi, ${ }^{1,4}$ Denis M. Larkin, ${ }^{2}$ Juan J. Loor, ${ }^{2}$ \\ Annelie Everts-van der Wind, ${ }^{2}$ Jun-Heon Lee, ${ }^{2}$ James K. Drackley, ${ }^{2}$ Mark R. Band, ${ }^{3}$ \\ A.G. Hernandez, ${ }^{3}$ Moshe Shani, ${ }^{1}$ Harris A. Lewin, ${ }^{2}$ Joel I. Weller, ${ }^{1,5}$ and Micha Ron ${ }^{1}$ \\ ${ }^{1}$ Institute of Animal Sciences, Agricultural Research Organization, Bet-Dagan 50250, Israel; ${ }^{2}$ Department of Animal Sciences and \\ ${ }^{3}$ W.M. Keck Center for Comparative and Functional Genomics, University of Illinois, Urbana, Illinois 61801, USA
}

\begin{abstract}
We previously localized a quantitative trait locus (QTL) on chromosome 6 affecting milk fat and protein concentration to a 4-cM confidence interval, centered on the microsatellite BM143. We characterized the genes and sequence variation in this region and identified common haplotypes spanning five polymorphic sites in the genes IBSP, SPP1, PKD2, and ABCG2 for two sires heterozygous for this QTL. Expression of SPP1 and ABCG2 in the bovine mammary gland increased from parturition through lactation. SPP1 and all the coding exons of $A B C G 2$ and PKD2 were sequenced for these two sires. The single nucleotide change capable of encoding a substitution of tyrosine-581 to serine (Y581S) in the $A B C G 2$ transporter was the only polymorphism corresponding to the segregation status of all 3 heterozygous and 15 homozygous sires for the QTL in the Israeli and U.S. Holstein populations. The allele substitution fixed effects on the genetic evaluations of 335 Israeli sires were $-341 \mathrm{~kg}$ milk, $+0.16 \%$ fat, and $+0.13 \%$ protein $(F$-value $=200)$. No other polymorphism gave significant effect for fat and protein concentration in models that also included Y581S. The allele substitution effects on the genetic evaluations of 670 cows, daughters of two heterozygous sires, were $-226 \mathrm{~kg}$ milk, $0.09 \%$ fat, and $0.08 \%$ protein $(F$-value $=394)$, with partial dominance towards the 581S homozygotes. We therefore propose that Y581S in ABCG2 is the causative site for this QTL.
\end{abstract}

[Supplemental material is available online at www.genome.org. The sequence data from this study have been submitted to EMBL/GenBank/DDB] under accession nos. A]871966, A]871964, A]871963, A]871176, A]871967, A]871968, A]871965, A]877268.]

Although many studies have demonstrated linkage between genetic markers and quantitative trait loci (QTL) in commercial animal populations, the actual DNA polymorphism responsible for the observed effect-a quantitative trait nucleotide (QTN), has been identified in only a single case in dairy cattle. Grisart et al. (2002) identified a polymorphism in exon 8 of the gene encoding acylCoA:diacyglycerol acyltransferase (DGAT1) on Bos taurus chromosome 14 (BTA 14), which was associated with increased fat yield, fat, and protein percent, as well as decreased milk and protein production. This gene was identified using bioinformatics, comparative mapping, and functional analysis (Grisart et al. 2002; Weller et al. 2003; Winter et al. 2002).

Segregating QTL for milk production traits on BTA6 were found in U.S. Holsteins (Georges et al. 1995; Zhang et al. 1998), Canadian Holsteins (Nadesalingam et al. 2001), Dutch Holsteins (Spelman et al. 1996), German Holsteins (Kuhn et al. 1999), British black and white cattle (Wiener et al. 2000), Norwegian cattle (Olsen et al. 2002), and Finnish Ayrshires (Velmala et al. 1999). Ron et al. (2001) found that three QTL affecting milk, fat, and

\footnotetext{
${ }^{4}$ These authors contributed equally to this work.

${ }^{5}$ Corresponding author.

E-mail weller@agri.huji.ac.il; fax 973-8-9470587.

Article and publication are at http://www.genome.org/cgi/doi/10.1101/ gr.3806705.
}

protein production, as well as fat and protein concentration, are segregating on BTA6 in the Israeli Holstein population. The QTL with the greatest significance was located near the middle of the chromosome, with a confidence interval of $4 \mathrm{cM}$ for protein percentage centered on microsatellite BM143. Two unrelated Israeli sires were found to be heterozygous for this QTL, whereas seven other sires were homozygous for the QTL.

The QTL confidence interval on BTA6 is orthologous to two regions on both arms of human chromosome 4 (HSA4) that contain the following annotated genes: FAM13A1, HERC3, HERC5, HERC6, PPM1K, ABCG2, PKD2, SPP1, MEPE, IBSP, LAP3, MED28, KIAA1276, HCAP-G, MLR1, and SLIT2 (Everts-van der Wind et al. 2004). Olsen et al. (2005) used physical mapping and combined linkage and linkage disequilibrium (LD) mapping to determine that this QTL is located within a $420-\mathrm{Kb}$ region between $A B C G 2$ and $L A P 3$.

In this study, we present very strong evidence for the second positional cloning of a QTL in an outbred cattle population. A single nucleotide polymorphism (SNP) capable of encoding a substitution of tyrosine-581 to serine in $A B C G 2$ is most likely responsible for the major QTL affecting milk yield and composition. Jonker et al. (2005) demonstrated that $A B G C 2$ is responsible for the active secretion of clinically and toxicologically important substrates into mouse milk, and that mice homozygous for 
an ABCG2 knock-out mutation lack this function. However, $-/-$ mice and their suckling progeny showed no adverse effects. It therefore remains unclear why $A B C G 2$ is functionally active in the mammary gland. This study sheds light on this important question, as the first example of a functional role for this gene in natural milk secretion.

\section{Results}

Comparative and physical mapping of the critical region for the BTA6 QTL

By combining comparative genomics and in silico gene cloning, we produced a map of genes and sequence variation in the critical region of the QTL (Fig. 1). We confirmed gene order by physical mapping of PCR probes in BAC clones that are part of genomic contigs 503 and 8342 (Supplemental Table 1). BM143 and SLIT2 were identified within contig 8342. Fifteen genes within 2 cM centromeric to BM143 were identified within contig 503 orthologous to two different regions on HSA4. Figure 1 shows the predicted order, size, and orientation of transcription of the genes within contig 503, based on their corresponding features in the human genome.

\section{Polymorphism detection, LD mapping, and haplotype analysis}

A total of 31,655 bp was sequenced in intergenic, exonic, and intronic regions of 10 genes within the critical region of the QTL using DNA of two sires (2278 and 3099) heterozygous for the QTL (Table 1). Thirteen sites heterozygous in at least one of the two

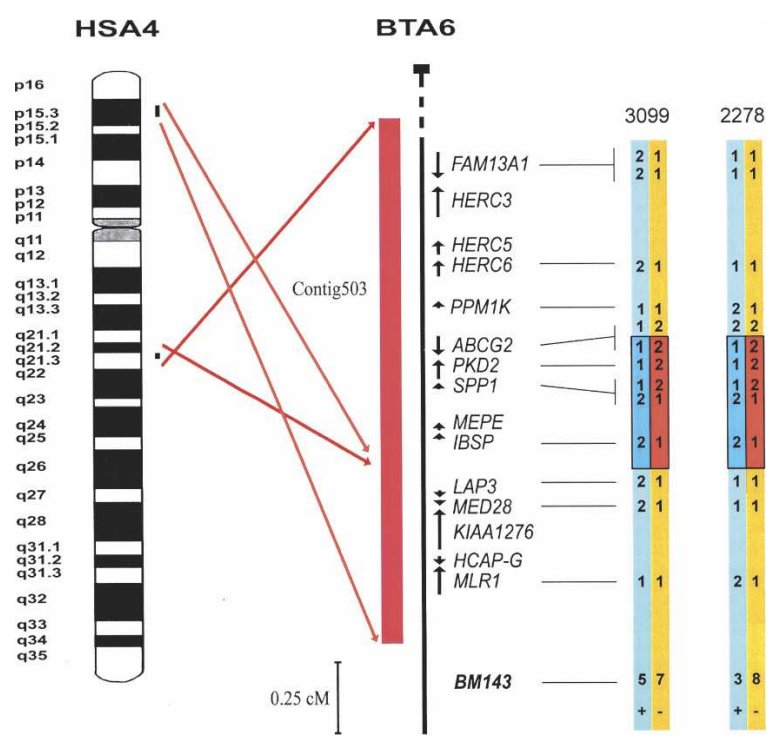

Figure 1. Genes within the critical region of the QTL on BTA6 proximal to BM143 were ordered based on the cattle-human genome comparative map, 23 bovine BAC clones representing contig 503, with SPP1, IBSP, and LAP3 as anchors for the orthologous regions on HSA4. BM143 is indicated (in boldface type) as the most informative marker for the QTL in cattle. Polymorphism is displayed at the respective gene positions for the two sires 2278 and 3099, heterozygous for the QTL (+/-). For the diallelic markers the allele with the higher frequency is denoted 1 , and the allele with the lower frequency is denoted 2. BM143 alleles were numbered consecutively from shortest to longest based on all alleles detected in the population. Shared haplotypes in concordance with the segregation status of the two sires for the QTL are displayed in red and blue. sires were selected as markers and genotyped for 411 sires. A single polymorphic site was genotyped in seven genes, and two polymorphic sites were genotyped in each of the three genes SPP1, ABCG2, and FAM131A1. Henceforth, the polymorphisms will be denoted by gene symbol for seven single-gene polymorphisms, and by the gene symbol followed by either (1) or (2) for the genes with two polymorphisms. All sites of polymorphism were in highly significant LD $(P<0.0001)$ with at least one other site. $\mathrm{LD}$ values of adjacent markers are plotted in Supplemental Figure 1. Generally, LD values between adjacent markers were $>0.2$. Exceptions were the BM143-MRL1-MED28 segment, LAP3IBSP, and HERC6-FAM13A1. The two sires heterozygous for the QTL share common haplotypes for the polymorphic sites at IBSP, SPP1, PKD2, and ABCG2 (Fig. 1). For both sires, the same haplotype was associated with increased protein concentration.

\section{Cloning of bovine $A B C G 2$, PKD2, and SPPI genes}

A bovine BAC clone containing the three genes SPP1, PKD2, and ABCG2 (GenBank accession no. AJ871176) was shotgun sequenced. By aligning this sequence with bovine ESTs and human orthologous genes, we identified in this BAC the last 15 exons of the bovine $A B C G 2$ gene, which included the whole putative polypeptide sequence of the $A B C G 2$ transporter (protein CAI38796.1). In the opposite orientation on the BAC, we annotated 15 exons of the gene orthologous to human PKD2 (CAI38797.1) and seven exons of bovine SPP1 (CAI38798.1). The entire description of the cloning procedure is presented in the Supplemental data.

\section{Expression of candidate genes in the bovine mammary gland}

Of the eight genes analyzed, three genes, SPP1, ABCG2, and $M E D 28$, showed significant differential expression in the mammary gland during lactation, as compared with the dry period $(P<0.02)$. Significant differential expression was not found in liver tissue. Expression of SPP1 and $A B C G 2$ in the mammary gland and liver during lactation and the dry period is shown in Figure 2 . The increase in the mammary gland was 8 - and 20 -fold for the two genes, respectively.

\section{The ABCG2 missense mutation Y581S}

Using this BAC data, we sequenced the exons, introns, and part of the regulatory region of SPP 1 and all of the coding exons of PKD2 and $A B C G 2$ for the two Israeli sires heterozygous for the QTL. The single nucleotide change, A to C, denoted ABCG2(2), capable of encoding a tyrosine-to-serine substitution at position 581 (Y581S) in the fifth extracellular region of the $A B C G 2$ protein, was detected. Henceforth, the A allele, capable of encoding tyrosine, which was the more frequent allele in the population, will be denoted the + QTL allele. The + allele decreases milk yield and thus increases fat and protein concentration. Of the 341 sires with valid genotypes, 12 were homozygotes $(-/-), 109$ were heterozygotes, and 220 were homozygotes $(+/+)$. The + QTL allele frequency was 0.805 . Thus, the genotype frequencies corresponded nearly exactly to the expected Hardy-Weinberg frequencies. $A B C G 2$ (2) was the only polymorphism corresponding to the segregation status of all three heterozygous and 15 homozygous sires for the QTL in the Israeli and US Holstein populations. The probability of concordance by chance, computed as described in the methods, is $\left(0.68^{15}\right)\left(0.16^{2}\right)=0.00008$. 
Table 1. Polymorphism detection in the course of positional cloning the QTL on BTA6

\begin{tabular}{|c|c|c|c|c|c|c|c|}
\hline \multirow[b]{2}{*}{ Gene } & \multicolumn{2}{|c|}{ Number of exons } & \multicolumn{3}{|c|}{ Sequencing size (bp) } & \multicolumn{2}{|c|}{ Polymorphism } \\
\hline & Total & Sequenced & Exons & Introns & Promoter & Type $^{a}$ & Location \\
\hline MLR1 & 7 & 2 & 482 & 228 & & Insertion TGAT & Exon 7 (AJ871966) \\
\hline MED28 & 5 & 2 & 133 & 1268 & & $C$ to $T$ & Exon 4 (AJ871964) \\
\hline LAP3 & 13 & 2 & 147 & 450 & & $\mathrm{C}$ to $\mathrm{T}$ & Exon 12 (AJ871963) \\
\hline IBSP & 7 & 1 & 560 & & & A to $G$ & Exon 7 (NM_174084 $\left.{ }^{\mathrm{b}}\right)$ \\
\hline SPP1(1) & 7 & 7 & 1362 & 5633 & 1205 & A to $G$ & Intron 5 (AJ871176) \\
\hline SPP1(2) & & & & & & $\mathrm{T}$ to $\mathrm{G}$ & Exon 7 (AJ871176) \\
\hline PKD2 & 15 & 15 & 3023 & 2485 & 2931 & Insertion A & Promoter (AJ871176) \\
\hline$A B C G 2(1)$ & 16 & $15^{\mathrm{c}}$ & 2029 & 3416 & & A to $T$ & Intron 3 (AJ871176) \\
\hline$A B C G 2(2)$ & & & & & & A to $C^{d}$ & Exon 14 (Aj871176) \\
\hline PPMIK & 7 & 1 & 490 & & & GC to AT & Exon 2 (AJ871967, AJ871968) \\
\hline HERC6 & 23 & & & 330 & & Insertion C & Intron 5 (A)877268) \\
\hline $\operatorname{FAM13A1(1)}$ & 18 & 18 & 2580 & 2190 & & A to $G$ & Intron 9 (Cohen et al. 2004a) \\
\hline FAM13A1(2) & & & & & & $\mathrm{C}$ to $\mathrm{A}$ & Exon 12 (Cohen et al. 2004a) \\
\hline Total & & & 10,806 & 16,713 & 4136 & & \\
\hline
\end{tabular}

${ }^{\mathrm{a}}$ The more frequent allele is listed first.

${ }^{\mathrm{b}}$ At position 802 .

${ }^{\mathrm{C} C o d i n g}$ region of this gene starts in exon 2.

dY581S.

\section{Allele substitution effects and dominance}

The Model 1 effects of the markers on the quantitative traits are given in Table 2 . This model estimated the effects associated with the polymorphisms on the sire evaluations for the milk production traits, with each polymorphism-trait combination analyzed separately (Cohen et al. 2004a). The number of bulls with valid genotypes and the frequency of the more common allele for each marker are also given. Most of the markers had highly significant effects on protein concentration, but the effect associated with $A B C G 2(2)$ was more than double the next largest effect. LAP3, MED28, ABCG2(2), and HERC6 had significant effects on fat and protein yield, whereas $A B C G 2(2), S P P 1(1), S P P 1(2)$, and PKD2 were associated with milk yield. The effect associated with $A B C G 2$ (2) on milk was double the next largest effect, and the effect associated with percentage fat was triple the next largest effect observed.

The effects on the quantitative traits associated with 670 daughters of the two sires heterozygous for the QTL are given in Table 3, both as class effects and as regression effects. The class effects are given relative to the $581 \mathrm{~S}$ homozygote $(-/-)$. Dominance was estimated from the class effects, relative to the $581 \mathrm{~S}$ homozygote. The regression effects estimated from the animal model analyses of the entire Israeli Holstein population are also given. Israel and Weller (1998) demonstrated that QTL effects

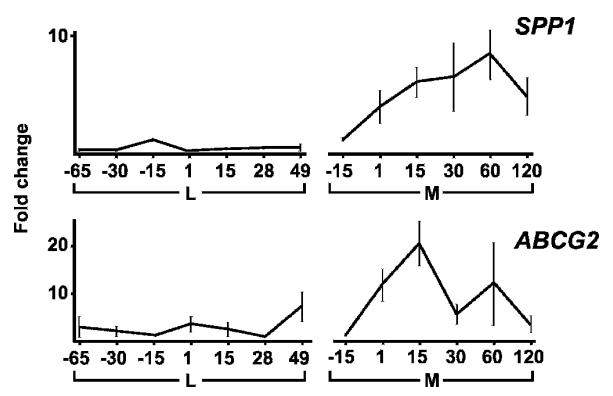

Figure 2. Expression data for $S P P 1$ and $A B C G 2$ in bovine mammary (M) and liver $(\mathrm{L})$ tissues. Fold-change values are normalized intensity during pregnancy $(-65,-30$, and $-15 \mathrm{~d}$ to calving date) and lactation $(1,15$, 30,60 , and $120 \mathrm{~d}$ postpartum) using day -15 as a base for comparison. will be underestimated by the analysis of genetic evaluations, especially genetic evaluations of cows, which have relatively low heritability, while estimates derived from animal model analyses of the entire population will be unbiased. The effects derived from the animal model for milk, percentage fat, and percentage protein were more than double the regression effects from the analyses of the genetic evaluations. This was not the case for fat and protein yield, but these effects were only marginally significant in the analyses of the genetic evaluations. For all five traits, the heterozygous effect was within the range of the two homozygous effects. Significant partial dominance was obtained for both percentage fat and percentage protein towards the 581S homozygote, which was also the less frequent allele among the daughters of the heterozygous sires.

\section{Variance components and marker substitution effects from REML analysis}

The numbers of genotyped bulls and ancestors included in the variance component analyses are given in Supplemental Table 4 for the analyses of $A B C G 2$ (2) alone, and the analyses of $A B C G 2(2)$ with SPP1(2), HERC6, and LAP3. These analyses are presented because these markers gave the greatest Model 1 effects on the production traits after $A B C G 2$ (2). In each analysis, the number of ancestors was slightly greater than the numbers of genotyped bulls. The total number of bulls included in each analysis ranged from 641 to 758 .

The variance components are presented in Table 4 for all four analyses. The residual effects were generally low, because genetic evaluations were analyzed. In all four analyses, the variance components and the substitution effects associated with $A B C G 2$ (2) for fat and protein percentage were quite similar. The substitution effects were close to $0.21 \%$ for both traits in all analyses. These values are also close to the values of $0.22 \%$ and $0.19 \%$ for fat and protein percentage obtained from the animal model analysis. The variance components for all the markers other than $A B C G 2(2)$ were near zero for fat and protein percentage. The variance components associated with SPP1(2) were near zero for all five traits. These results correspond to the hypothesis

\section{Genome Research}

www.genome.org 
Table 2. Effects of the polymorphisms on the bulls' breeding values for the quantitative traits with each marker analyzed separately

\begin{tabular}{|c|c|c|c|c|c|c|c|}
\hline \multirow[b]{2}{*}{ Marker } & \multirow[b]{2}{*}{ Number of bulls } & \multirow{2}{*}{$\begin{array}{l}\text { Frequency of the } \\
\text { more common allele }\end{array}$} & \multicolumn{5}{|c|}{ Quantitative traits } \\
\hline & & & Milk & Fat & Protein & $\%$ Fat & $\%$ Protein \\
\hline$B M 143^{a}$ & 346 & 55.1 & -34 & 0.7 & $-3.5^{\star *}$ & 0.019 & $-0.022^{\star}$ \\
\hline MLR1 & 298 & 50.5 & -67 & -2.8 & 0.7 & -0.005 & $0.025^{*}$ \\
\hline MED28 & 316 & 57.2 & 80 & $6.0^{\star * *}$ & $4.4^{\star * \star}$ & 0.031 & $0.018^{*}$ \\
\hline LAP3 & 341 & 57.3 & 13 & $6.1^{\star *}$ & $4.7^{* * *}$ & $0.053^{* *}$ & $0.039^{* * * *}$ \\
\hline$I B S P$ & 336 & 61.3 & -35 & 1.1 & 0.6 & 0.021 & 0.015 \\
\hline SPP1(1) & 366 & 57.0 & $-123^{\star *}$ & -0.1 & 0.8 & $0.039 *$ & $0.043^{* * * *}$ \\
\hline SPP1(2) & 309 & 72.9 & $-171 * *$ & -0.7 & 1.4 & $0.048^{*}$ & $0.061^{* * * *}$ \\
\hline PKD2 & 326 & 67.1 & $-141^{\star *}$ & 0.6 & 0.9 & $0.046^{*}$ & $0.048^{* * * *}$ \\
\hline$A B C G 2(2)^{b}$ & 335 & 80.5 & $-341^{* \star * *}$ & $5.3^{*}$ & $4.1^{\star *}$ & $0.159^{\star \star \star \star}$ & $0.135^{* \star \star \star}$ \\
\hline$A B C G 2(1)$ & 282 & 55.4 & -67 & 0.8 & 2.4 & 0.029 & $0.042^{* * * *}$ \\
\hline PPMIK & 369 & 73.6 & -58 & -1.7 & 1.8 & 0.001 & $0.033^{* *}$ \\
\hline HERC6 & 328 & 67.9 & -14 & $4.9^{\star *}$ & $5.6^{* \star \star *}$ & $0.049^{* *}$ & $0.056^{* \star * *}$ \\
\hline FAM13A1(1) & 381 & 81.8 & -64 & 0.3 & 1.1 & 0.023 & $0.028^{*}$ \\
\hline FAM13A1(2) & 370 & 41.1 & $-107^{*}$ & 2.0 & 1.2 & $0.053^{* *}$ & $0.042^{* * * *}$ \\
\hline
\end{tabular}

Significance: ${ }^{*}, p<0.05 ;{ }^{* *}, p<0.01 ;{ }^{* * *}, p<0.001 ;{ }^{* * *}, p<0.0001$.

aThis microsatellite was analyzed as a diallelic marker as described in the Supplemental data.

bFor $A B C G 2(2)$ effects were computed relative to the Y581 allele. This allele, denoted the + allele, was associated with increased protein concentration. For all the other markers, the effects were computed relative to the allele in LD association with the + allele for $A B C G 2(2)$.

that $A B C G 2(2)$ is the causative mutation for the QTL affecting fat and protein concentration.

The variance component associated with ABCG2(2) for milk was similar in all analyses, except for the analysis that included HERC6. In this analysis, the variance component for ABCG2(2) increased to 160,000 . This can be explained by postulating that two QTL are segregating on this chromosome that affect milk production, and that, in general, these two QTL are in repulsion throughout the population. Thus, a greater effect was observed associated with ABCG2(2) with HERC6 included in the model, because the "masking" effect was removed. These results correspond to the previous results of Ron et al. (2001) that found three QTL segregating on this chromosome. Sire 2278 was also segregating for the QTL proximate to the centromere, but the effects on milk were in repulsion for this sire. Thus, the effects associated with HERC6 correspond to the QTL proximate to the centromere described previously by Ron et al. (2001). This QTL affects milk, fat, and protein production but not fat or protein concentration. The effects associated with $L A P 3$ partially correspond to the third segregating QTL also described by Ron et al. (2001), which chiefly affected milk and fat yield and protein concentration. Unlike the analyses including $A B C G 2(2)$ and HERC6, in the analyses includ- ing $A B C G 2(2)$ and $L A P 3$, the variance components associated with both markers were positive for fat and protein yield. This corresponds to the hypothesis that neither of these markers is in complete linkage for the QTL responsible for fat and protein yield.

\section{Genetic trend}

The genetic trend for the $581 Y$ of $A B C G 2(2)$ in the entire cow population is shown in Figure 3. The mean annual breeding values for fat and protein percent are also given. The frequency of $581 Y$ allele by birth date of cows decreased from 0.75 in 1982 to 0.62 in 1990, and then increased to 0.77 in 2002. These trends correspond to the change in the Israeli breeding index, which was based chiefly on milk production until 1990. Since then, the index has been based chiefly on protein with a negative weight for milk yield (Weller et al. 2003).

\section{Conservation of $A B C G 2581$ in mammals}

Comparison of this protein domain across mammals is presented in Figure 4 for the region spanning amino acid 557 to 630 . The arrow indicates position 581, for which tyrosine and serine were

Table 3. Effect of $A B C G 2(2)$ on the breeding values of the daughters of the heterozygous sires and QTL effects derived from the animal model analyses

\begin{tabular}{|c|c|c|c|c|c|c|c|}
\hline \multirow[b]{2}{*}{ Analysis } & \multirow[b]{2}{*}{ Genotype $^{a}$} & \multirow{2}{*}{$\begin{array}{l}\text { Number } \\
\text { of cows }\end{array}$} & \multicolumn{5}{|c|}{ Quantitative traits } \\
\hline & & & Kg milk & $\mathrm{Kg}$ fat & $\mathrm{Kg}$ protein & $\%$ Fat & $\%$ Protein \\
\hline Class effects ${ }^{\mathrm{b}}$ & $\begin{array}{l}-1- \\
+/- \\
+/+\end{array}$ & $\begin{array}{r}78 \\
328 \\
264\end{array}$ & $\begin{array}{c}0 \\
-185 \\
-432^{\star \star \star \star}\end{array}$ & $\begin{array}{l}0 \\
0.4 \\
4.2^{* \star}\end{array}$ & $\begin{array}{l}0 \\
1.2 \\
3.3^{* *}\end{array}$ & $\begin{array}{l}0 \\
0.059 \\
0.169^{\star * \star *}\end{array}$ & $\begin{array}{l}0 \\
0.065 \\
0.145^{\star \star \star \star *}\end{array}$ \\
\hline $\begin{array}{l}\% \text { Dominance }^{c} \\
\text { Regression }^{d} \\
\text { Animal model }^{d}\end{array}$ & & 670 & $\begin{aligned} & 14.3 \\
- & 226^{\star \star \star \star \star} \\
- & 597\end{aligned}$ & $\begin{array}{l}80.9 \\
2.6^{\star *} \\
2.2\end{array}$ & $\begin{array}{l}27.3 \\
1.8^{\star \star} \\
1.3\end{array}$ & $\begin{array}{l}30.2^{*} \\
0.093^{* * * *} \\
0.225\end{array}$ & $\begin{array}{l}17.2^{*} \\
0.076^{\star * * *} \\
0.193\end{array}$ \\
\hline
\end{tabular}

Significance: ${ }^{*}, p<0.05 ;{ }^{* *}, p<0.01 ;{ }^{* * *}, p<0.001 ; * * * *, p<0.0001$.

a581S was denoted the "-" QTL allele; Y581 was denoted the "+" QTL allele.

bSignificance of the class effect is indicated in the $+/+$ row. Effects are computed relative to the $-/-$ homozygote.

'Relative to the $-/$ - homozygote.

${ }^{\mathrm{d}}$ Allele substitution effects assuming additivity. 
Table 4. Variance components and marker substitution effects from REML analysis of the sire evaluations

\begin{tabular}{|c|c|c|c|c|c|}
\hline & \multicolumn{5}{|c|}{ Trait } \\
\hline & Kg milk & Kg fat & Kg protein & $\%$ Fat & $\%$ Protein \\
\hline \multicolumn{6}{|c|}{ Variance components } \\
\hline$A B C G 2(2)$ & 86,640 & 13.0 & 12.9 & 0.0145 & 0.0128 \\
\hline Polygenic & 272,720 & 553.0 & 286.4 & 0.0481 & 0.0101 \\
\hline Residual & 84,504 & 1.2 & 0.1 & 0.0005 & 0.0001 \\
\hline \multicolumn{6}{|c|}{ Substitution effects ${ }^{a}$} \\
\hline$A B C G 2(2)$ & 520 & 6.4 & 6.3 & 0.213 & 0.200 \\
\hline \multicolumn{6}{|c|}{ Variance components } \\
\hline$A B C G 2(2)$ & 103,080 & 2.71 & 5.1 & 0.0135 & 0.0129 \\
\hline SPP1(2) & 0 & 0.0 & 0.0 & 0.0000 & 0.0000 \\
\hline Polygenic & 270,550 & 563.0 & 289.1 & 0.0480 & 0.0096 \\
\hline Residual & 77,542 & 1.6 & 0.0 & 0.0000 & 0.0007 \\
\hline \multicolumn{6}{|c|}{ Substitution effects } \\
\hline$A B C G 2(2)$ & 568 & 2.9 & 4.0 & 0.213 & 0.201 \\
\hline SPP1(2) & 0 & 0.0 & 0.0 & 0.000 & 0.000 \\
\hline \multicolumn{6}{|c|}{ Variance components } \\
\hline$A B C G 2(2)$ & 161,952 & 0 & 0 & 0.0158 & 0.0153 \\
\hline HERC6 & 15,178 & 20.6 & 22.6 & 0 & 0 \\
\hline Polygenic & 267,670 & 521.3 & 282.3 & 0.0456 & 0.0093 \\
\hline Residual & 86,103 & 1.0 & 0.1 & 0 & 0.0002 \\
\hline \multicolumn{6}{|c|}{ Substitution effects ${ }^{a}$} \\
\hline$A B C G 2(2)$ & 711 & 0 & 0 & 0.222 & 0.219 \\
\hline HERC6 & 218 & 8.0 & 8.4 & 0 & 0 \\
\hline \multicolumn{6}{|c|}{ Variance components } \\
\hline$A B C G 2(2)$ & 85,277 & 4.7 & 8.4 & 0.0133 & 0.0134 \\
\hline$\angle A P 3$ & 2697 & 9.2 & 7.1 & 0 & \\
\hline Polygenic & 291,069 & 556.9 & 286.0 & 0.0493 & 0.0094 \\
\hline Residual & 77,829 & 1.0 & 0 & 0 & 0 \\
\hline \multicolumn{6}{|c|}{ Substitution effects ${ }^{a}$} \\
\hline$A B C G 2(2)$ & 516 & 3.8 & 5.1 & 0.204 & 0.205 \\
\hline LAP3 & 92 & 5.4 & 4.7 & 0 & 0 \\
\hline
\end{tabular}

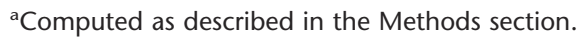

found for the three sires heterozygous for the QTL. Phenylalanine is the conserved amino acid in the mammals analyzed, except for Canis familiaris and Bos taurus with tyrosine at this position. Both tyrosine and phenylalanine are aromatic acids, whereas serine is a nucleophilic acid.

\section{Discussion}

As of 2002, the molecular basis of approximately 30 genes was found for complex traits (Glazier et al. 2002), with only one documented gene in cattle, DGAT1 on BTA14, which chiefly affects milk fat concentration (Grisart et al. 2002).

Various studies have proposed candidate genes for the QTL on BTA6 based on their putative physiological role on the trait of interest (Wayne and McIntyre 2002). Weikard et al. (2004) suggested that PPARGC1A (peroxisome proliferator activated receptor gamma, coactivator 1 , alpha) is a positional and functional candidate gene for the QTL on BTA6, because of its key role in energy, fat, and glucose metabolism. Olsen et al. (2005) postulated that the function of PKD2 best corresponds with the QTL effect. This gene encodes an integral membrane protein involved in intracellular calcium homeostasis and other signal transduction pathways (Nauli et al. 2003). Cohen et al. (2004b) suggested that SPP1 has an essential role in mammary gland differentiation and branching of the mammary epithelial ductal system, and is therefore a prime candidate. Furthermore, anti-sense SPP1 transgenic mice displayed abnormal mammary gland differentiation and milk secretion (Nemir et al. 2000).

Mackay (2001) postulated that the only option to achieve the standard of rigorous proof for identification of a gene underlying a QTL in commercial animal populations is to collect "multiple pieces of evidence, no single one of which is convincing, but which together consistently point to a candidate gene."

In this study, diverse pieces of evidence support the conclusion that $A B C G 2$ is the segregating QTL on BTA6:

1. The shared haplotypes of the two sires segregating for the QTL spanned five sites of polymorphism in the genes IBSP, SPP1, $P K D 2$, and $A B C G 2$. This is equivalent to the $420-\mathrm{Kb}$ region found in the Norwegian cattle (Olsen et al. 2005), except that it is shorter on the $5^{\prime}$ end of $A B C G 2$ (exons 1 to 3 ) and the $3^{\prime}$

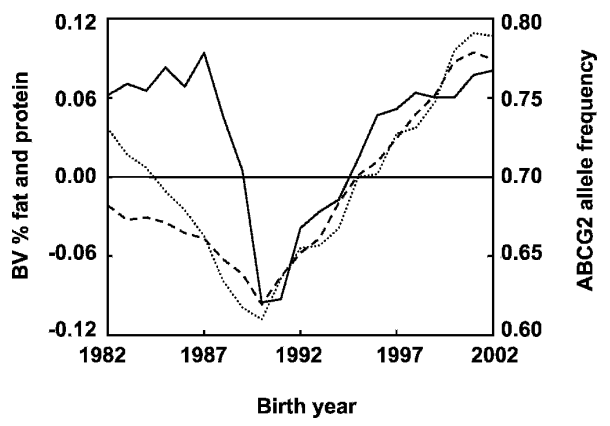

Figure 3. Genetic trends for protein and fat concentration and frequency of the $A B C G 2581 \mathrm{Y}$ allele in the Israeli Holstein cow population by birth year. (Solid line) ABCG2 581Y allele frequency; (dotted line) mean yearly breeding values for \% fat; (broken line) mean yearly breeding values for $\%$ protein.

\section{Genome Research}

www.genome.org 


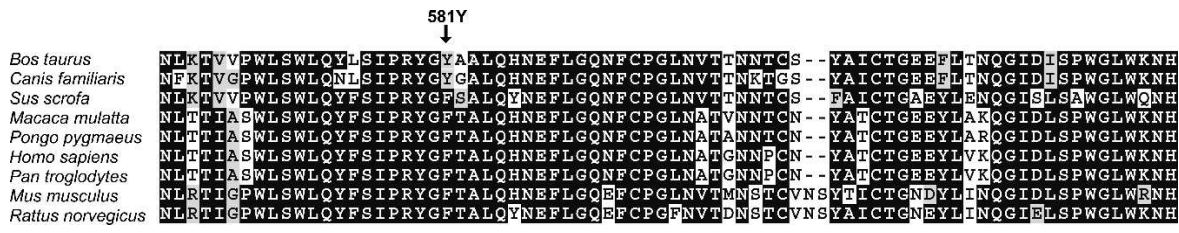

Figure 4. Conservation of the $5^{\text {th }}$ extracellular domain of $A B C G 2$ protein in mammals. The ClustalW (Thompson et al. 1994) alignment of predicted amino acid sequences of nine orthologous $A B C G 2$ genes is shown. Identity and similarity between the amino acid sequences are indicated by black and gray boxes, respectively. White boxes indicate nonconservative amino acid changes between the proteins. Dashes indicate gaps introduced by the alignment program. The position of $581 \mathrm{Y}$ in Bos taurus for which the sires heterozygous for the QTL were 581Y/581S is indicated by an arrow. A conserved phenylalanine residue is located in this position for most of the other mammals.

end of LAP3 (exons 12 and 13). The same haplotype was associated with the + QTL allele in both sires.

2. The two genes within the shared haplotype, ABCG2 and SPP1, were preferentially expressed in the bovine mammary gland at the onset of lactation. Furthermore, large-scale analysis of human and mouse transcriptomes revealed that $A B C G 2$ had the highest expression in the mammary among 61 organs and tissues tested (Su et al. 2002).

3 . Of the polymorphisms genotyped, only $A B C G 2(2)$ was in concordance with the segregation status of all 3 heterozygous and 15 homozygous sires for the QTL in the Israeli and U.S. Holstein populations. The probability that this would occur by chance is 0.00008 .

4. $A B C G 2(2)$ is capable of encoding a non-conservative amino acid change (Y581S) that may affect this gene's transporter function.

5. The highest population-wide substitution effects on milk yield and fat and protein concentration were obtained for the Y581S polymorphism in $A B C G 2$, and these effects were more than double the next largest effects associated with any of the other polymorphisms.

6. In the analysis of over 300 genotyped bulls, none of the other polymorphisms gave significant effects for fat and protein concentration in models that also included Y581S.

7. The high Y581S allele substitution effects on the genetic evaluations of 670 cows, daughters of two heterozygous sires, represent the joint effects of both paternal and maternal alleles. The $F$-value was 394 for percentage protein.

8. Protein and fat concentration for cows homozygous for the $581 \mathrm{~S}$ allele was lower than the heterozygotes, even though the second $581 \mathrm{~S}$ allele was of maternal origin, and therefore unrelated to the daughter design effects.

9. The frequency of $581 \mathrm{Y}$ allele by birth date of cows decreased from 0.75 in 1982 to 0.62 in 1990, and then increased to 0.77 in 2002, in correspondence with the changes in the Israeli Holstein selection index. The close correspondence between the two analyses supports the conclusion that $A B C G 2(2)$ is the QTN, although it could also be due to a "hitch-hiker" effect (Weichenhan et al. 2001).

10. Weller et al. (2002) estimated the frequency of the + QTL allele in the Israeli Holstein population as 0.69 and 0.63 , relative to fat and protein percent, by the modified granddaughter design for cows born between 1992 and 1996. This corresponds closely to the frequency of 0.69 for $581 Y$ as estimated in the current study for cows born in 1994.

Schnabel et al. (2005) proposed that OPN3907 in the regulatory region of SPP1 is the QTN. We sequenced all 18 Israeli and US sires with known QTL genotypes, and found that this chromosomal segment is hyper-variable. At least four single nucleotide changes were found within the 20-bp region centered on the poly-A sequence. All sires except one were heterozygous for at least one of these polymorphisms. We thus conclude that OPN3907 is not the QTN. However, as long as the entire chromosomal segment within the confidence interval of the QTL has not been sequenced in the sires with known QTL genotypes, it is not possible to completely eliminate the possibility that the QTN may be some other polymorphism in strong LD with Y581S. Furthermore, formal proof that this polymorphism is in fact the QTN can only be obtained by functional studies (Grisart et al. 2004).

None of the other markers displayed significant effects on fat and protein concentration in models that also included ABCG2(2). However, this was not the case for milk, fat, and protein yield. These results correspond to the results of several studies that indicate multiple QTL affecting milk production traits segregating on this chromosome (Ron et al. 2001; Olsen et al. 2005). Ron et al. (2001) found that the other QTL were at some distance from the major QTL affecting fat and protein concentration, but confidence intervals for QTL location are quite large for QTL of moderate effects (Weller 2001). The LD effects observed in this study may indicate that the additional QTL are in fact quite close to $A B C G 2$.

The genetic and economical potential of the identification of the gene is quite modest for the Holstein populations analyzed, in which the + QTL allele is already at a high frequency. At present, allelic frequencies in other populations are unknown. In a recent study, Kaupe et al. (2004) estimated the allele frequency of DGAT1 polymorphism in 38 cattle breeds representing the entire range from zero to fixation.

$A B C G 2$, a member of the ATP binding cassette (ABC) superfamily, is a "halftransporter," with only one ATP binding cassette in the $\mathrm{N}$ terminus and one $\mathrm{C}$-terminal transmembrane domain (Ejendal and Hrycyna 2002; Gottesman et al. 2002). In an ATPdependent process, $A B C G 2$ transports various xenobiotics and cytostatic drugs across the plasma membrane (Litman et al. 2000). Analysis of different stages of mammary development by immunohistochemistry and Western analysis revealed that $A B C G 2$ was not expressed in virgin mice but was greatly induced during late pregnancy and especially during lactation (Jonker et al. 2005). They demonstrated that $A B C G 2$ expression is confined to the apical membrane of alveolar, but not ductal mammary epithelial cells of mice, cows, and humans and is responsible for the active secretion of clinically and toxicologically important substrates into mouse milk. $A B C G 2$ is thought to be a drug transporter, but it is induced by estrogen. Related genes, namely, $A B C G 1, A B C G 5$, and $A B C G 8$ are sterol transporters (Schmitz et al. 2001). It is therefore reasonable to propose that $A B C G 2$ might transport cholesterol into milk.

Whereas in other tissues $A B C G 2$ generally has a xenotoxinprotective function, transfer of xenotoxins from the mother to the suckling infant or young via milk is difficult to reconcile with a protective role. Our study provides the first example of a functional role for this gene in natural milk secretion. The effect of 
the specific Y581S polymorphism on the activity of the ABCG2 protein remains to be explored.

\section{Methods}

PCR primers and their corresponding numbers are presented in Supplemental Table 3.

\section{Physical mapping and bioinformatics}

The order and location of the genes in the QTL region were determined in the bovine bacterial artificial chromosomes (BACs) from the CHORI-240 BAC library (Warren et al. 2000). We used repeat-masked end sequences from CHORI-240 clones obtained from the GenBank for BLASTN search against the human genome sequence (NCBI build 33). The cattle fingerprint contigs (BCCRC, Vancouver, British Columbia, Canada) were identified that contain clones anchored to the human genome by sequence similarity. Cattle fingerprint contig 503, which covers the confidence interval region of the QTL upstream to BM143 in HSA4, is diagramed in Figure 1. The contig is represented on the axis of HSA4 in the following positions: 89,077,921-90,827,214 and 17,255,215-17,699,645 (http://genome.ucsc.edu/cgi-bin/ hgGateway?org=human). A minimum tiling path of 23 cattle BACs, listed in the Supplemental data, between these positions covering the region of the QTL from FAM13A1 to MLR1 were selected. The exact position of each gene in the human genome was identified using the UCSC Genome Browser database. Bovine BAC clones presumably containing the same gene in cattle were identified by their end sequence similarity to the human genome and are presented in Supplemental Table 1. When there was no BAC clone with both ends covering the whole interval of the candidate gene, several overlapping BACs with single ends matching the upper and lower boundaries of the gene interval and covering the whole region were selected for PCR analysis. The BAC templates were prepared by picking colonies grown overnight and boiling them in $200 \mu \mathrm{L}$ of $\mathrm{ddH}_{2} \mathrm{O}$ for $10 \mathrm{~min}$. Bioinformatics procedures, management of DNA sequences and EST assembly were done as previously described (Cohen et al. 2004a).

\section{Identification of polymorphism in genes within the critical region of the QTL}

To search for relevant informative genomic variation in the critical region of the QTL we used the genomic DNA of the two sires heterozygous for the QTL as a template. We PCR amplified genomic fragments of the bovine orthologs of the human genes listed in Table 1. In most cases, we obtained the bovine sequence required for the design of PCR primers from bovine ESTs of the orthologous genes. The PCR products were sequenced for polymorphism detection. Nucleotide substitution was detected by double peaks for the specific nucleotides, and insertion was detected by sequence overlap that was analyzed using ShiftDetector (Seroussi et al. 2002). The entire description of the cloning and the identification of polymorphism procedures for HERC6, PPM1K, ABCG2, PKD2, SPP1, IBSP, LAP3, MED28, and MLR1 are presented in the Supplemental data.

\section{Experimental design and haplotype analysis}

The search for the QTN was based on genotyping of the following samples:

1. Two sires heterozygous for the QTL (2278 and 3070) and seven sires homozygous for the QTL in the Israeli population as determined using a daughter design (Ron et al. 2001).

2. A single sire heterozygous for the QTL (DBDR family 9) and eight sires homozygous for the QTL in the US population
(DBDR family 1 to 8 ) as determined using a granddaughter design analysis (Ashwell et al. 2004).

3. Six hundred seventy daughters of two Israeli sires heterozygous for the QTL with genetic evaluations for production traits (Ron et al. 2001).

4. Four hundred eleven progeny-tested Israeli sires with genetic evaluations for production traits (Cohen et al. 2004a).

5. Eight cows with mammary biopsies and five cows with liver biopsies.

The 411 Israeli Holstein sires with genetic evaluations for all five milk production traits were genotyped for the 13 markers listed in Table 1 and BM143. Eleven markers were SNPs, one was a two-base polymorphism, and two were microsatellites (BM143, and the polymorphic site in MLR1). Twenty daughters of each of the two Israeli sires heterozygous for the QTL were also genotyped for all 14 markers to determine the haplotypes of the two sires. Genotyping of polymorphism was performed following the methods of Cohen et al. (2004a). The genotyping platform and specific assay for each site are presented in Supplemental Table 2.

\section{Statistical analysis}

LD parameters values were computed between each pair of markers as described by Hedrick (1987). Probability of concordance by chance between the QTL and a polymorphism was computed only for $A B C G 2(2)$, which was the only marker in complete concordance with the 18 sires with known QTL genotype (Ron et al. 2001; Ashwell et al. 2004). Since only polymorphisms heterozygous in at least one of the sires heterozygous for the QTL were genotyped on the complete sample of bulls, the probability of concordance with the QTL only considered the remaining 17 sires. This is computed as the probability that all 15 sires homozygous for the QTL should also be homozygous for the polymorphism, and that the two remaining sires heterozygous for the QTL should also be heterozygous for the polymorphism, and that in all three heterozygous sires the same QTL allele should be associated with the same marker allele. Thus probability of concordance is $\mathrm{p}_{1}{ }^{15}\left(\mathrm{p}_{2} / 2\right)^{2}$, where $\mathrm{p}_{1}$ is the probability of homozygotes, and $\mathrm{p}_{2}$ is the probability of heterozygotes. $\mathrm{P}_{2}$ was divided by two, because for concordance to be complete, the two additional heterozygous sires must have the same $A B C G 2(2)$ allele associated with the + QTL allele as the original genotyped sire.

Genetic evaluations for milk, fat, and protein were computed by a multi-trait animal model analysis of the entire Israeli Holstein population (Weller and Ezra 2004). Evaluations for fat and protein percent were derived from the evaluations for the production traits. The following fixed linear model, denoted Model 1, was used to estimate the effect associated with each one of the polymorphisms for each of five traits analyzed (Cohen et al. 2004a):

$$
\mathrm{Y}_{\mathrm{ijkl}}=\mathrm{a}_{\mathrm{i}} \mathrm{J}+\mathrm{b}_{\mathrm{i}} \mathrm{K}+\mathrm{c}_{\mathrm{i}}(\mathrm{K})^{2}+\mathrm{e}_{\mathrm{ijkl}}
$$

where $Y_{i j k l}$ is the genetic evaluation of sire 1 with marker genotype $j$ and birth year $k$ for trait $i$; $J$ is the number of + alleles $(j=0$, 1 , or 2); $\mathrm{K}$ is the sire's birth year; $\mathrm{a}_{\mathrm{i}}, \mathrm{b}_{\mathrm{i}}$, and $\mathrm{c}_{\mathrm{i}}$ are regression coefficients for trait $\mathrm{i}$; and $\mathrm{e}_{\mathrm{ijkl}}$ is the random residual for each sire for trait i. The + allele for $A B C G 2(2)$ was the allele associated with increased protein concentration. For all of the other markers, the allele in LD association with the + for ABCG2(2) was denoted the + allele. BM143 was analyzed as a diallelic marker, as described in the Supplemental data. The linear and quadratic effects of the sires' birth year were included to account for genetic trends in the population. The effects of the markers were also analyzed with three marker genotypes as class effects. Linear and quadratic birth year trends of the markers were also estimated.

\section{Genome Research}

www.genome.org 
Model 1 does not account for the relationships among sires or linkage among markers. Thus, the genetic evaluations were also analyzed for a subset of the markers with the greatest effects by the following model, denoted Model 2:

$$
\mathrm{Y}_{\mathrm{ijk}}=\mathrm{a}_{\mathrm{i}} \mathrm{J}+\mathrm{g}_{\mathrm{ik}}+\mathrm{e}_{\mathrm{ijk}}
$$

where $g_{i k}$ is the additive polygenic effect for animal $k$ on trait $i$, and the other terms are as defined previously. This model differed from the previous model in that all three effects were considered random, and the numerator relationship matrix was used to compute the variance matrix for the polygenic effect. To obtain a more complete relationship structure, all known parents and maternal grandsires of the genotyped bulls were included in the analysis. The numbers of animals in each analysis are given in Supplemental Table 2. REML variance components were computed for the "a" and "g" effects by the MTC program (http:// nce.ads.uga.edu/ ignacy/oldprograms.html). Marker substitution effects were derived as: [(Var a)/(2pq) $]^{1 / 2}$ where "Var a" is the marker variance component, and $\mathrm{p}$ and $\mathrm{q}$ are the frequencies of the two QTL alleles, as derived from the sample of 411 genotyped sires (Weller 2001). This model was also used to analyze marker pairs with highly significant effects on the quantitative traits as determined by Model 1 .

Dominance of the QTL effect can only be estimated by comparison of cows that are heterozygous for the QTL with cows that are homozygous for the two alternative alleles (Weller et al. 2003). The genetic evaluations for the five milk production traits of 670 daughters of two Israeli sires heterozygous for the QTL were analyzed by a model that also included the sire effect. The QTL was considered a class effect and significance of dominance was estimated by significance of the difference between the midpoint of the two homozygote effects and the mean of the heterozygote effect. The dominance effect was estimated as the ratio of the difference between the heterozygote effect and the midpoint of the homozygote effects, divided by half the difference between the homozygote effects. Cow genetic evaluations are based on relatively few records and are therefore highly regressed. Thus, the QTL effects estimated from this model will also be underestimated (Israel and Weller 1998). However, this should not have a major effect on the estimate of dominance, which was derived as a ratio of the estimated effects.

Genotype probabilities for $A B C G 2(2)$ were determined for the entire Israeli Holstein milk-recorded population, including 600,478 cows and 1670 bulls, using the segregation analysis algorithm of Kerr and Kinghorn (1996), based on the 335 bulls with valid genotypes. Finally, the QTL effects for milk, fat, and protein yield were estimated from the entire Israeli Holstein milkrecorded population based on the genotyped cows, as proposed by Israel and Weller (1998). These QTL estimates should be unbiased, unlike the estimates derived from analysis of the genetic evaluations. The effects for fat and protein percent were derived from the estimated effects for the yield traits as described by Weller et al. (2003).

The detailed procedures for biopsy procedures, RNA extraction, BAC clone selection, subcloning and shotgun sequencing, real-time PCR, and computation of $\mathrm{LD}$ parameter values and ABCG2(2) genotype probabilities for the entire Israeli Holstein population are presented in the Supplemental data.

\section{Acknowledgments}

This research was supported by grants from the Israel Milk Marketing Board, the US-Israel Binational Agricultural Research and Development fund (BARD), and the USDA-CSREES Livestock Ge- nome Sequencing Initiative (to HAL). Genotyping was performed at the Genome Knowledge Center, the Weizmann Institute of Science, supported by the Israel Ministry of Science and the Crown Human Genome Center. We thank B. Kinghorn and I. Misztal for use of their programs and E. Ezra for his help in data retrieval from the Israeli herd-book.

\section{References}

Ashwell, M.S., Heyen, D.W., Sonstegard, T.S., Van Tassell, C.P., Da, Y., VanRaden, P.M., Ron, M., Weller, J.I., and Lewin, H.A. 2004. Detection of quantitative trait loci affecting milk production, health and reproductive traits in Holstein cattle. J. Dairy Sci. 87: 468-475.

Cohen, M., Reichenstein, M., Everts-van der Wind, A., Heon-Lee, J., Shani, M., Lewin, H.A., Weller, J.I., Ron, M., and Seroussi, E. 2004a. Cloning and characterization of FAM13A1-A gene near a milk protein QTL on BTA6: Evidence for population-wide linkage-disequilibrium in Israeli Holsteins. Genomics 84: 374-383.

Cohen, M., Seroussi, E., Band, M.R., Lewin, H.A., Drackley, J.K., Larkin, D.M., Everts-van der Wind, A., Heon-Lee, J., Loor, J.J., Shani, M., et al. 2004b. SPP1 is a candidate gene for the QTL affecting milk protein concentration on BTA6 in Israeli Holstein. 29th Int. Conf. Ani. Gen., ISAG, F015, Tokyo, Japan.

Ejendal, K.F. and Hrycyna, C.A. 2002. Multidrug resistance and cancer: The role of the human ABC transporter ABCG2. Review. Curr. Protein Pept. Sci. 3: 503-511.

Everts-van der Wind, A., Kata, S.R., Band, M.R., Rebeiz, M., Larkin, D.M., Everts, R.E., Green, C.A., Liu, L., Natarajan, S., Goldammer, T., et al. 2004. A 1463-gene cattle-human comparative map with anchor points defined by human genome sequence coordinates. Genome Res. 14: 1424-1437.

Georges, M., Nielsen, D., Mackinnon, M., Mishra, A., Okimoto, R., Pasquino, A.T., Sargeant, L.S., Sorensen, A., Steele, M.R., and Zhao, X. 1995. Mapping quantitative trait loci controlling milk production in dairy cattle by exploiting progeny testing. Genetics 139: 907-920.

Glazier, A.M., Nadeau, J.H., and Aitman, T.J. 2002. Finding genes that underlie complex traits. Science 298: 2345-2349.

Gottesman, M.M., Fojo, T., and Bates, S.E. 2002. Multidrug resistance in cancer: Role of ATP-dependent transporters. Nat. Rev. Cancer 2: $48-58$.

Grisart, B., Coppieters, W., Farnir, F., Karim, L., Ford, C., Berzi, P., Cambisano, N., Mni, M., Reid, S., Simon, P., et al. 2002. Positional candidate cloning of a QTL in dairy cattle: Identification of a missense mutation in the bovine DGAT1 gene with major effect on milk yield and composition. Genome Res. 12: 222-231.

Grisart, B., Farnir, F., Karim, L., Cambisano, N., Kim, J.J., Kvasz, A., Mni, M., Simon, P., Frere, J.M., Coppieters, W., et al. 2004. Genetic and functional confirmation of the causality of the DGAT1 K232A quantitative trait nucleotide in affecting milk yield and composition. Proc. Natl. Acad. Sci. 101: 2398-2403.

Hedrick, P.W. 1987. Gametic diequilibrium measures: Proceed with caution. Genetics 117: 331-341.

Israel, C. and Weller, J.I. 1998. Estimation of candidate gene effects in dairy cattle populations. J. Dairy Sci. 81: 1653-1662.

Jonker, J.W., Merino, G., Musters, S., van Herwaarden, A.E., Bolscher, E., Wagenaar, E., Mesman, E., Dale, T.C., and Schinkel, A.H. 2005. The breast cancer resistance protein BCRP (ABCG2) concentrates drugs and carcinogenic xenotoxins into milk. Nat. Med. 11: 127-129.

Kaupe, B., Winter, A., Fries, R., and Erhardt, G. 2004. DGAT1 polymorphism in Bos indicus and Bos Taurus cattle breeds. Anim. Genet. 71: 182-187.

Kerr, R.J. and Kinghorn, B.P. 1996. An efficient algorithm for segregation analysis in large populations. J. Anim. Breed. Genet. 113: $457-469$.

Kuhn, C., Freyer, G., Weikard, R., Goldammer, T., and Schwerin, M. 1999. Detection of QTL for milk production traits in cattle by application of a specifically developed marker map of BTA6. Anim. Genet. 30: 333-340.

Litman, T., Brangi, M., Hudson, E., Fetch, P., Abati, A., Ross, D.D., Miyake, K., Resau, J.H., and Bates, S.E. 2000. The multidrug-resistant phenotype associated with overexpression of the new $\mathrm{ABC}$ half-transporter, MXR (ABCG2). J. Cell Sci. 113: 2011-2021.

Mackay, T.F. 2001. The genetic architecture of quantitative traits. Annu. Rev. Genet. 35: 303-339.

Nadesalingam, J., Plante, Y., and Gibson, J.P. 2001. Detection of QTL for milk production on Chromosomes 1 and 6 of Holstein cattle. Mamm. Genome 12: 27-31.

Nauli, S.M., Alenghat, F.J., Luo, Y., Williams, E., Vassilev, P., Li, X., Elia, 
A.E., Lu, W., Brown, E.M., Quinn, S.J., et al. 2003. Polycystins 1 and 2 mediate mechanosensation in the primary cilium of kidney cells. Nat. Genet. 33: 129-137.

Nemir, M., Bhattacharyya, D., Li, X., Singh, K., Mukherjee, A.B., and Mukherjee, B.B. 2000. Targeted inhibition of osteopontin expression in the mammary gland causes abnormal morphogenesis and lactation deficiency. J. Biol. Chem. 275: 969-976.

Olsen, H.G., Gomez-Raya, L., Vage, D.I., Olsaker, I., Klungland, H., Svendsen, M., Adnoy, T., Sabry, A., Klemetsdal, G., Schulman, N., et al. 2002. A genome scan for quantitative trait loci affecting milk production in Norwegian dairy cattle. J. Dairy Sci. 85: 3124-3130.

Olsen, H.G., Lien, S., Gautier, M., Nilsen, H., Roseth, A., Berg, P.R., Sundsaasen, M., Svendsen, K.K., and Meuwissen, T.H. 2005.

Mapping of a milk production QTL to a $420 \mathrm{~kb}$ region on bovine chromosome 6. Genetics 169: 275-283.

Ron, M., Kliger, D., Feldmesser, E., Seroussi, E., Ezra, E., and Weller, J.I. 2001. Multiple QTL analysis of bovine chromosome 6 in the Israeli Holstein population by a daughter design. Genetics 159: 727-735.

Schmitz, G., Langmann, T., and Heimer, D. 2001. Role of ABCG1 and other ABCG family members in lipid metabolism. J. Lipid Res. 49: $1513-1520$.

Schnabel, R.D., Kim, J.-J., Ashwell, M.S., Sonstegard, T.S., Van Tassel, C.P., Connor, E.E., and Taylor, J.F. 2005. Fine-mapping milk production quantitative trait loci on BTA6: Analysis of the bovine osteopontin gene. Proc. Natl. Acad. Sci. 102: 6896-6901.

Seroussi, E., Ron, M., and Kedra, D. 2002. ShiftDetector: Detection of frame shift mutations. BioInformatics 18: 1137-1138.

Spelman, R.J., Coppieters, W., Karim, L., van Arendonk, J.A.M., and Bovenhuis, H. 1996. Quantitative trait loci analysis for five milk production traits on chromosome six in the Dutch Holstein-Friesian population. Genetics 144: 1799-1808.

$\mathrm{Su}$, A.I., Cooke, M.P., Ching, K.A., Hakak, Y., Walker, J.R., Wiltshire, T., Orth, A.P., Vega, R.G., Sapinoso, L.M., Moqrich, A., et al. 2002. Large-scale analysis of the human and mouse transcriptomes. Proc. Natl. Acad. Sci. 99: 4465-4470.

Thompson, J.D., Higgins, D.G., and Gibson, T.J. 1994. Improved sensitivity of profile searches through the use of sequence weights and gap excision. Comput. Appl. Biosci. 10: 19-29.

Velmala, R.J., Vilkki, H.J., Elo, K.T., de Koning, D.J., and Maki-Tanila, A.V. 1999. A search for quantitative trait loci for milk production traits on chromosome 6 in Finnish Ayrshire cattle. Anim. Genet. 30: $136-143$.

Warren, W., Smith, T.P.L., Rexroad, C.E., Fahrenkrug, S.C., Allison, T., Shu, C.L., Catanese, J., and de Jong, P.J. 2000. Construction and characterization of a new bovine bacterial artificial chromosome library with 10 genome-equivalent coverage. Mamm. Genome 11: $662-663$.
Wayne, M.L. and McIntyre, L.M. 2002. Combining mapping and arraying: An approach to candidate gene identification. Proc. Natl. Acad. Sci. 99: 14903-14906.

Weichenhan, D., Kunze, B., Winking, H., Michel van Geel, M.v., Osoegawa, K., Jong, P.J., and Traut, W. 2001. Source and component genes of a 6-200 Mb gene cluster in the house mouse. Mamm. Genome 12: 590-594.

Weikard, R., Kuhn, C., Goldammer, T., Freyer, G., and Schwerin, M. 2004. PPARGC1Aa candidate gene for a QTL on BTA6 affecting milk fat synthesis. 29th Int. Conf. Ani. Gen., ISAG, D060, Tokyo, Japan.

Weller, J.I. 2001. Quantitative trait loci analysis in animals. CABI Publishing, London.

Weller, J.I. and Ezra, E. 2004. Genetic analysis of the Israeli Holstein dairy cattle population for production and non-production traits with a multitrait animal model. J. Dairy Sci. 87: 1519-1527.

Weller, J.I., Weller, H., Kliger, D., and Ron, M. 2002. Estimation of quantitative trait locus allele frequency via a modified granddaughter design. Genetics 162: 841-849.

Weller, J.I., Golik, M., Seroussi, E., Ezra, E., and Ron, M. 2003. Population-wide analysis of a QTL affecting milk-fat production in the Israeli Holstein population. J. Dairy Sci. 86: 2219-2227.

Wiener, P., Maclean, I., Williams, J.L., and Woolliams, J.A. 2000. Testing for the presence of previously identified QTL for milk production traits in new populations. Anim. Genet. 31: 385-395.

Winter, A., Kramer, W., Werner, F.A., Kollers, S., Kata, S., Durstewitz, G., Buitkamp, J., Womack, J.E., Thaller, G., and Fries, R. 2002. Association of a lysine-232/alanine polymorphism in a bovine gene encoding acyl-CoA:diacylglycerol acyltransferase (DGAT1) with variation at a quantitative trait locus for milk fat content. Proc. Natl. Acad. Sci. 99: 9300-9305.

Zhang, Q., Biochard, D., Hoeschele, C., Ernst, A., and Eggen, A. 1998. Mapping quantitative trait loci for milk production and health of Dairy cattle in a large outbreed pedigree. Genetics 149: 1959-1973.

\section{Web site references}

http://genome.ucsc.edu/cgi-bin/hgGateway?org=human; Human Genome Browser Gateway.

http://nce.ads.uga.edu/ ignacy/oldprograms.html; Threshold model programs.

http://cowry.agri.huji.ac.il/web/; Biopsy procedures.

Received February 8, 2005; accepted in revised form April 13, 2005.

944 Genome Research

www.genome.org 


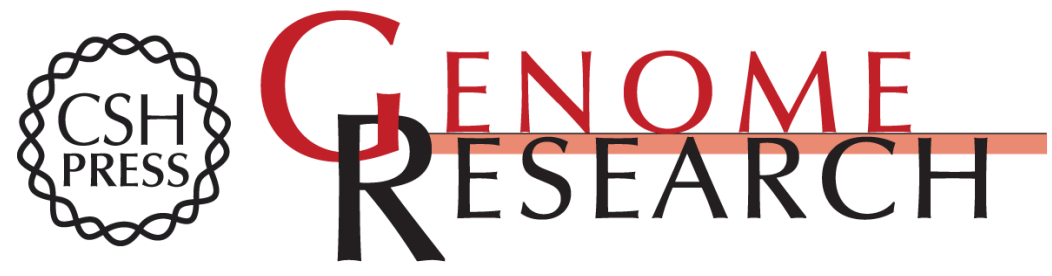

\section{Identification of a missense mutation in the bovine $A B C G 2$ gene with a major effect on the QTL on chromosome 6 affecting milk yield and composition in Holstein cattle}

Miri Cohen-Zinder, Eyal Seroussi, Denis M. Larkin, et al.

Genome Res. 2005 15: 936-944

Access the most recent version at doi:10.1101/gr.3806705

Supplemental http://genome.cshlp.org/content/suppl/2005/06/22/15.7.936.DC1
Material

References This article cites 39 articles, 17 of which can be accessed free at:

http://genome.cshlp.org/content/15/7/936.full.html\#ref-list-1

\section{License}

Email Alerting Receive free email alerts when new articles cite this article - sign up in the box at the Service top right corner of the article or click here.

\section{Affordable, Accurate Sequencing.}

